\title{
Recurrent Erysipelas in Myotonic Dystrophy Type 1 with IgG Deficiency
}

\author{
M. Hofer ${ }^{a}$ C. Stöllberger ${ }^{b} \quad$ J. Finsterer ${ }^{b}$ \\ ${ }^{\mathrm{a}}$ 2nd Medical Department, Krankenanstalt Rudolfstiftung, and ${ }^{\mathrm{b}}$ Krankenanstalt Rudolfstiftung, Vienna, Austria
}

Dear Sir,

Dystrophia myotonica type 1 (DM1), the most common muscular dystrophy in adults, is a hereditary, autosomal dominant, multi-system disease, caused by a CTG repeat expansion in a non-coding region of the dystrophia myotonica protein kinase (DMPK) gene on chromosome $19 q 13.3[1,2]$. DM1 is frequently associated with IgG deficiency [3], which is independent of the CTG repeat size [4]. Here we report a DM1 patient with IgG deficiency and recurrent erysipelas.

The patient is a 61-year-old HIV-negative female with a history of recurrent erysipelas, occurring 4 times during the last 5 years. The erysipelas developed twice in the face (2001 and 2002) and twice in the gluteal region (2003 and September 2005). Her relatives reported increasing cognitive impairment and social regression during the last 6 years. In February 2005 she was admitted because of gait disturbance from weakness of the distal lower limbs. Clinical neurological examination revealed ptosis, dysarthria, weakness for foot extension (M5-), wasting of the distal upper and lower limb muscles, clinical myotonia and absent Achilles tendon reflexes. Nerve conduction studies were normal but electromyography revealed myotonic discharges and myogenic motor unit architecture. Ophthalmological examination showed incipient cataract bilaterally. Blood chemical investigations revealed slightly elevated glutamate oxalate transaminase but nor-

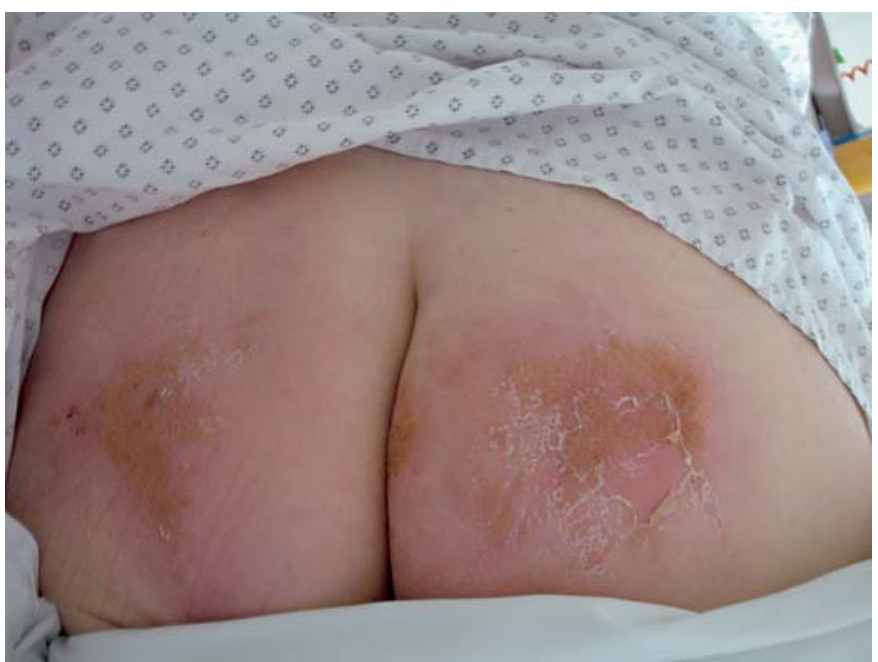

Fig. 1. Widespread erysipela in the gluteal region 7 days after onset in May 2006 (fifth episode) in the described DM1 patient.

mal creatine kinase. Clinical cardiological examination and echocardiography were normal but electrocardiography showed arteriovenous block I and left anterior hemiblock. Molecular genetic analysis revealed a CTG expansion of 130 repeats in the DMPK gene. The diagnosis of DM1 was established. After the last episode of gluteal erysipelas in September 2005, she underwent a long-term oral penicillin therapy for 6 months until February 2006.
In May 2006 she was re-admitted because of fever up to $39.3^{\circ} \mathrm{C}$ and somnolence for 3 days. The skin in the gluteal region presented with an extensive bilateral erysipelas (fig. 1). This was altogether the fifth episode of an erysipela, the third in the gluteal region. The C-reactive protein was $11.6 \mathrm{mg} / \mathrm{dl}$ (normal: $<0.6 \mathrm{mg} / \mathrm{dl}$ ), $\alpha_{1^{-}}$ globulin $5.0 \%$ (normal: $1.5-4.0 \%$ ), but the leucocyte count and coagulation parameters were normal. The total serum IgG was

\section{KARGER}

Fax +4161306 1234 E-Mail karger@karger.ch www.karger.com
(C) 2007 S. Karger AG, Basel 0014-3022/07/0574-0236\$23.50/0

Accessible online at:

www.karger.com/ene
Univ.-Prof. DDr. J. Finsterer

Postfach 20

AT-1180 Vienna (Austria)

Tel. +431 71165, Fax +4314781711

E-Mail duarte@aonmail.at 
reduced to $547 \mathrm{mg} / \mathrm{dl}$ (normal: 700-1,600 $\mathrm{mg} / \mathrm{dl}$ ). IgG subtypes were not determined. Chest X-ray showed no pulmonary infiltration. Clinical neurological examination was unchanged compared to previous findings. Cerebrospinal fluid examination was normal. Electrocardiography showed a normocardiac sinus rhythm and missing R progression. Under parenteral treatment with penicillin G (10 million IU/day) and flucloxacillin (6 g/day), fever and C-reactive protein decreased and the vigilance improved.

Decreased IgG is a well-known, previously described feature of DM1 but usually remains asymptomatic $[5,6]$. Recurrent infections are usually no clinical characteristic of DM1. Only in single DM1 patients was hypogammaglobulinaemia associated with an increased rate of infections [6]. On the contrary, it has been shown that the prevalence of chronic lower respiratory tract infections, recurrent herpes simplex infections and recurrent erysipelas was increased among 313 patients with hereditary serum IgG deficiency, particularly those with IgG3 deficiency [7]. Whether recurrent erysipela in the presented patient are attributable to hypoIgG-aemia or a mere arbitrary coincidence and why hypo-IgG-aemia was particularly associated with recurrent erysipelas and not more common infections remain speculative.

This case suggests DM1 with hypoIgG-aemia to be prone to recurrent erysipelas. This is the first report of a patient with DM1, low serum IgG and recurrent erysipelas.

\section{References}

1 Schara U, Schoser BG: Myotonic dystrophies type 1 and 2: a summary on current aspects. Semin Pediatr Neurol 2006;13:71-79.

2 Day JW, Ranum LP: Genetics and molecular pathogenesis of the myotonic dystrophies. Curr Neurol Neurosci Rep 2005;5:55-59.

3 Nakamura A, Kojo T, Arahata K, Takeda S: Reduction of serum IgG level and peripheral T-cell counts are correlated with CTG repeat lengths in myotonic dystrophy patients. Neuromuscul Disord 1996;6:203210.
4 Pan-Hammarstrom Q, Wen S, GhanaatPour H, Solders G, Forsberg H, Hammarstrom L: Lack of correlation between the reduction of serum immunoglobulin concentration and the CTG repeat expansion in patients with type 1 dystrophia myotonica. J Neuroimmunol 2003;144:100-104.

5 Schneider-Gold C: Myotonic dystrophy: present management, future therapy; in Harper PS, van Engelen BGM, Eymard B, Wilcox DE (eds): Human Genetics, ed 1. Oxford, Oxford University Press, 2004.

6 Mouthon L, Godmer P, Piqueras B, Cohen P, Lortholary O, Hofmann-Radvanyi H, Guillevin L: Giardia lamblia infection in a patient with myotonic dystrophy. Ann Méd Interne (Paris) 2002;153:540-542.

7 Oxelius VA, Hanson LA, Bjorkander J, Hammarstrom L, Sjoholm A: IgG3 deficiency: common in obstructive lung disease, hereditary in families with immunodeficiency and autoimmune disease; in Hanson LA, Shakib F (eds): Immunoglobulin Subclass Deficiencies. Monogr Allergy. Basel, Karger, 1986, vol 20, pp 106-115. 